\title{
Multiresidue Determination of Pesticides in Carrots using Pressurized Liquid Extraction and Gas Chromatography with Mass Spectrometry Detector
}

\author{
Fernanda C. Abad, Priscila R. Winck, Juliana M. da Silva, \\ Elina B. Caramão and Cláudia A. Zini* \\ Instituto de Química, Universidade Federal do Rio Grande do Sul, \\ Av. Bento Gonçalves, 9500, 91501-970 Porto Alegre-RS, Brazil
}

\begin{abstract}
Neste estudo, 14 agrotóxicos (captan, clorotalonil, deltametrina, dicloran, fention, folpete, iprodiona, linurom, malationa, prometrina, procloraz, procimidona, triclorfom e trifluralina) foram usados no desenvolvimento de um método multiresíduos (MRM), utilizando extração de cenouras com líquido pressurizado (PLE). A etapa de clean-up foi realizada por dispersão da matriz em fase sólida (MSPD), sendo testados como material dispersante o Florisil, XAD-4, XAD-7 e C18. Diclorometano, acetato de etila e acetona foram empregados como solventes para PLE, a $75^{\circ} \mathrm{C}$ e 1.500 psi. As recuperações dos analitos para cenouras liofilizadas ficaram na faixa de 70 a $133 \%$. Entretanto, os percentuais de recuperação obtidos para as cenouras úmidas não foram satisfatórios $(<70 \%)$. Os coeficientes de determinação das curvas analíticas situaram-se na faixa de 0,9821 a 0,9997; os limites de detecção (LOD) e de quantificação (LOQ) para os vários compostos investigados ficaram entre $0,0024-0,1968 \mathrm{mg} \mathrm{kg}^{-1}$ e entre $0,0072-0,5963 \mathrm{mg} \mathrm{kg}^{-1}$, respectivamente.
\end{abstract}

In this study, 14 pesticides (captan, chlorothalonil, deltamethrin, dicloran, fenthion, folpet, iprodione, linuron, malathion, prometryn, prochloraz, procymidone, trichlorphon and trifluralin) were employed for developing a multiresidue method (MRM) using pressurized liquid extraction (PLE). In situ clean-up was achieved using matrix solid phase dispersion (MSPD), where Florisil, XAD-4, XAD-7 and C18 were tested as dispersing material for carrot samples. Dichloromethane, ethyl acetate and acetone were used as solvents in a PLE unit at $75^{\circ} \mathrm{C}$ and 1,500 psi. Recovery was in the range of 70 to $133 \%$. Results obtained with wet carrots were not satisfactory, since most of the recovery values were below 70\%. Determination coefficients of the analytical curves presented values between 0.9821 and 0.9970 . Limits of detection (LOD) and quantification (LOQ) for the various components varied from 0.0024 to $0.1968 \mathrm{mg} \mathrm{kg}^{-1}$, and 0.0072 to $0.5963 \mathrm{mg} \mathrm{kg}^{-1}$, respectively.

Keywords: multiresidue method, PLE, MSPD, carrots, GC/MS

\section{Introduction}

In the last few decades, pesticides have been used on an increasingly wider scale throughout the world. On account of the large number of active ingredients used in agricultural production, complex analytical procedures are required for the detection of a great number of possible compounds, with few number of extraction and clean-up steps. These compounds are characterized by their diversity, their different physical and chemical properties (polarity, solubility, pKa etc) and their low concentrations in real samples. ${ }^{1}$ Some of the analytical methods aim to determine a single component (SRM) and others, more sophisticated,

*e-mail: cazini@iq.ufrgs.br are capable of simultaneously determine more than one residue in a single analysis. These last ones are called pesticide multiresidue methods (MRM) and comprise a higher degree of analytical difficulty. Multiresidue methodology by definition requires determinative steps for separating analytes from one another so each one can be detected and measured individually. ${ }^{2}$ The most frequently used classical MRM (solid-liquid extraction) employs solvent extraction with acetone or ethyl acetate followed by gas chromatography determination. ${ }^{3}$

In recent years, some faster and more automated techniques for solid samples have been presented in the literature as an alternative to traditional solid-liquid extraction, such as supercritical-fluid extraction (SFE), microwave-assisted extraction (MAE) and pressurized 
liquid extraction (PLE), also known as accelerated solvent extraction (ASE). ${ }^{4,5}$ The main advantages of SFE are the ease separation of the extracted solute from the solvent, the possibility of obtaining clean extracts with reduced solvent consumption and the reduced extraction time, where extracts can often be analyzed with no further clean-up. ${ }^{6,7}$ However, nowadays the use of SFE has decreased dramatically during the last years, due to high cost of instrumentation and difficulties in method development concerning the extraction conditions optimization. ${ }^{8}$ Microwave pretreatment has as main advantages the low temperature requirement, high extraction efficiency, complete automation and the possibility of simultaneously extracting different samples at the same time without interference. A disadvantage of MAE seems to be lack of selectivity compared with SFE for comparable extraction efficiency, resulting in co-extraction of significant amounts of interfering compounds. Additional clean-up is therefore needed before chromatographic analysis. ${ }^{6}$

Pressurized liquid extraction uses solvents that are raised to the near-supercritical region, where they show better extraction properties. PLE takes advantage of the increased analyte solubility and extraction kinetics at higher temperature to speed the extraction process and reduce solvent consumption. ${ }^{9}$ At high temperatures, the rate of extraction increases because the viscosity and the surface tension decreases, while its solubility and diffusion rate into the sample increase. Pressure has less influence on analyte recoveries than temperature in PLE, but elevated pressure maintains the solvent in the liquid state at temperatures above the boiling point, and this helps the solvent transport through the sample. ${ }^{10}$ The combined use of high pressures and temperatures provides a faster extraction process that requires smaller amounts of solvent compared with traditional extraction, thus decreasing the dilution of the sample. ${ }^{9}$ The main disadvantages of PLE are that sample clean-up is still required after extraction and also that it requires very expensive equipment. Particular attention should also be paid to PLE performed at high extraction temperature, which may lead to degradation of thermally labile compounds. ${ }^{5}$

The majority of the studies concerning pesticides (by SRM or MRM) extraction using PLE are related to soil and sediment samples. ${ }^{11-13}$ Regarding fresh vegetables samples there are only a few studies in the literature dealing with MRM analysis, even though analytical methods for this kind of samples are extremely important for food quality control. ${ }^{11,14,15}$

Matrix solid phase dispersion (MSPD), a process for the extraction of target compounds from solid matrices was introduced by Barker et al. ${ }^{16}$ in 1989. MSPD combines both sample homogenization and a possible preliminary clean-up of the target compounds. ${ }^{17,18}$ Advantages of this procedure are that no emulsion is formed and elution of the analytes is performed with a relative small solvent volume. ${ }^{19}$ This technique also enhances the availability of the analytes as it promotes the disruption of the gross architecture of the sample. ${ }^{20-22}$ MSPD has been employed by some authors along with PLE as a simultaneous clean-up procedure in the extraction of pesticides from food samples. ${ }^{23}$ The literature reports just a few studies regarding SRM and MRM, which employ MSPD/PLE. These research works deal only with a single class of pesticides or with one residue chemical class, such as atrazine in kidney, ${ }^{9}$ carbamates in bovine milk $^{24}$ and fruits and vegetables, ${ }^{25}$ sulfonamides in raw meat and infant foods, ${ }^{26}$ pyrethroids in meats, cheeses, fruits, vegetables and starches, ${ }^{27}$ organochlorines in lettuce, tomato, spinach, potato, turnip leaf and green beans. ${ }^{28}$ As far as these authors are concerned there are only a few reports in the literature about a multiclass MSPD/PLE method applied to fruits and vegetables. Soler et al. ${ }^{29}$ determined twelve different chemical classes of pesticides in fruits. The samples were mixed with acidic alumina using a glass mortar and pestle before pressurized liquid extraction.

In this study, 14 pesticides (captan, chlorothalonil, deltamethrin, dicloran, fenthion, folpet, iprodione, linuron, malathion, prometryn, prochloraz, procymidone, trichlorphon and trifluralin) from 9 different classes (dicarboximide, organophosphorous, imidazolecarboxamide, isophthalonitrile, pyrethroid, organochlorine, phenylurea, triazine and dinitroaniline) were investigated. A multiresidue method for wet and freeze-dried (lyophylized) carrots samples was developed using PLE simultaneously with MSPD, having Florisil, XAD-4, XAD-7 and C18 as dispersion agents, and dichloromethane, ethyl acetate and acetone as solvents.

\section{Experimental}

\section{Reagents and materials}

Standard pesticides with purities of $95-99 \%$ were purchased from Riedel-de Haën (Seelze, Germany), internal standard (1,3,5-tribromobenzene) was supplied by SigmaAldrich, St. Louis, USA. Acetone, dichloromethane (DCM) and ethyl acetate (EA) were purchased from Carlo Erba (Milano, Italy), bi-distilled and kept in glass bottles with glass cap. Single and mixed standard stock solutions and their further dilutions were prepared in ethyl acetate. Solutions were stored at $-18{ }^{\circ} \mathrm{C}$ in a freezer. Dispersing agents employed for MSPD were Amberlite resins XAD4 (Prolabo, France) and XAD-7 (Fluka, France), Florisil 
(J.T. Baker, EUA) with particle diameter between 140 and $250 \mu \mathrm{m}$, modified silica gel (Fluka, Switzerland) with 17 to $18 \%$ of C18, Celite 545 (Nuclear, Rio de Janeiro) and anhydrous sodium sulphate (Merck, Darmstadt, Germany). All sorbents were activated or conditioned prior to use. All materials employed in the extraction process were rigorously washed with distilled water, acetone and heptane. Glassware was further dried at $300{ }^{\circ} \mathrm{C}$ for $3 \mathrm{~h}$, except for volumetric flasks. Glassware silanization was performed with dichloromethylsilane in toluene (Acros Organics, Belgium).$^{30}$

\section{Sampling and sample preparation}

Carrot samples, free of pesticides, were purchased from a local farmer's market ("Cooperativa Central dos Assentados no Rio Grande do Sul") in Porto Alegre. Samples were stored without foliage inside a glass vessel at $-18{ }^{\circ} \mathrm{C}$ until utilization. The developed method was applied to commercial carrot samples proceeding from two different states in Brazil.

Frozen carrots were employed as such and are called "wet (or fresh) samples" in this text. Other frozen carrots were ground in a metal liquidizer (power of $800 \mathrm{~W}$ ) and then freeze dried (lyophilized) in a Modular Lyophilizator 5260, model 4KEDWARD. Replicates of humidity determination were made using an infra-red balance model Martin ID200 CE96.

Matrix solid-phase dispersion (MSPD) and pressurized fluid extraction (PLE)

Ground wet carrots free of pesticides were fortified with a portion of the working solution in a stainless steel mortar to reach a final concentration of $0.5 \mu \mathrm{g} \mathrm{g}^{-1}$ (wet basis). Six grams of ground carrots were set aside to obtain a blank extract. The fortified sample was divided into portions of $6 \mathrm{~g}$ and to each fraction $3 \mathrm{~g}$ of different dispersion agents (XAD-4, XAD-7, C18, Florisil and anhydrous sodium sulphate) were added. Enough anhydrous sulphate was mixed with the wet carrot samples in order to obtain a flowing mixture. Dichloromethane, ethyl acetate and acetone were tested as solvents for MSPD/PLE.

MSPD was applied for freeze-dried and wet samples. The elution step of MSPD was performed by the ASE instrument. Pressurized liquid extractions were performed in a Dionex accelerated solvent extraction apparatus (ASE $\left.300^{\mathrm{TM}}\right)$. Extraction conditions were $1,500 \mathrm{psi}, 75^{\circ} \mathrm{C}, 5 \mathrm{~min}$ of extraction, $100 \%$ flush, $90 \mathrm{~s}$ purge and 2 cycles of extraction. This number of cycles was employed because former publications related to pesticides in food and other applications showed no further increase in analytes recovery after 2 or 3 cycles of extractions. ${ }^{31}$ The extraction conditions used for lyophilized carrots were the same described for wet carrots. Glass pearls were added to fulfill the empty space left by the lower volume of lyophilized carrots samples. Fortification was performed after the lyophilization process. In order to avoid sodium sulphate dissolution and further deposition in the ASE 300 tubings, Celite 545 (diatomaceous earth) was employed when acetone was the extracting solvent.

\section{Chromatographic conditions}

A GC/MS Shimadzu model QP5050-A, equipped with a capillary column OV-5, $30 \mathrm{~m} \times 0.25 \mathrm{~mm} \times 0.25 \mu \mathrm{m}$, containing 5\% phenyl-methylpolysiloxane (Ohio Valley, Marietta, Ohio), and having helium as carrier gas $\left(1.6 \mathrm{~mL} \mathrm{~min}^{-1}\right)$ was used at the following conditions: $90^{\circ} \mathrm{C}$ for $5 \mathrm{~min} ; 5^{\circ} \mathrm{C} \min ^{-1}$ to $102^{\circ} \mathrm{C} ; 7^{\circ} \mathrm{C} \mathrm{min}^{-1}$ to $160{ }^{\circ} \mathrm{C} ; 2^{\circ} \mathrm{C}$ $\min ^{-1}$ to $205^{\circ} \mathrm{C} ; 7^{\circ} \mathrm{C} \mathrm{min}^{-1}$ to $250{ }^{\circ} \mathrm{C} ; 5^{\circ} \mathrm{C} \mathrm{min}^{-1}$ to $280^{\circ} \mathrm{C}$. The injector was set to $250^{\circ} \mathrm{C}$ in splitless mode and the interface was kept at $280^{\circ} \mathrm{C}$. Electron impact ionization mode, with $70 \mathrm{eV}$ electron energy, was selected. The screening analysis was performed in the SIM (selective ion monitoring) mode, recording at least one characteristic ion for each compound. Monitoring of chosen ions was done according to specific retention time windows for each of the analytes, as shown in Table 1.

Table 1. Mass spectrometer detector parameters used in the selective ion monitoring mode for 14 pesticides and internal standard (IS)

\begin{tabular}{|c|c|c|c|}
\hline \multirow[t]{2}{*}{ Analyte } & \multirow{2}{*}{$\begin{array}{c}\text { Characteristic } \\
\text { ions }(\mathrm{m} / \mathrm{z})\end{array}$} & \multicolumn{2}{|c|}{ Acquisition window } \\
\hline & & $\begin{array}{l}\text { Acquisition } \\
\text { time (min) }\end{array}$ & $\begin{array}{c}\text { Monitoring } \\
\text { ions }(\mathrm{m} / \mathrm{z})\end{array}$ \\
\hline Trichlorphon & 109 & $5-12$ & 109 \\
\hline Tribromobenzene (IS) & 316 & $12-17$ & 316 \\
\hline Trifluralin & 264,306 & $17-25$ & $\begin{array}{l}124,176,206 \\
264,266,306\end{array}$ \\
\hline Dicloran & $124,176,206$ & & \\
\hline Chlorothalonil & 264,266 & & \\
\hline Prometryn & 184,241 & $25-30$ & $\begin{array}{c}61,93,125 \\
184,241,278\end{array}$ \\
\hline Linuron & 61 & & \\
\hline Malathion & 93,125 & & \\
\hline Fenthion & $93,125,278$ & & \\
\hline Captan & 79 & $30-35$ & $76,79,96,104$ \\
\hline Folpet & 76,104 & & \\
\hline Procymidone & 96 & & \\
\hline Iprodione & 187,244 & $35-42$ & 187,244 \\
\hline Prochloraz & 180 & $42-51$ & 180 \\
\hline Deltamethrin & 181 & $51-61$ & 181 \\
\hline
\end{tabular}




\section{Method validation}

Validation is the process of determining the methodology suitability achieving useful analytical data and should be performed to provide evidence that a method fits the purpose of its use. ${ }^{32,33}$ The following parameters were determined: analytical curve and linearity, limit of detection (LOD), limit of quantification (LOQ), accuracy (recovery) and precision (repeatability and intermediate precision). Calibration curves were evaluated using solutions of the pesticides in acetone in five different concentrations, ranging from 0.025 to $2.5 \mathrm{mg} \mathrm{L.}{ }^{-1}$ Each solution was chromatographically analyzed five times. Tribromobenzene was employed as internal standard resulting in a concentration of $1 \mathrm{mg} \mathrm{L}^{-1}$ in the final solutions. The LOD is the smallest concentration of analyte detectable in the sample by an analytical method with a given level of confidence, and the LOQ is the lowest solute concentration that can be determined with an acceptable level of uncertainty. ${ }^{34,35}$ LOD and LOQ were determined according to the ICH (International Conference on Harmonization) guideline which suggests calculation based as 3.3 and 10 times the ratio between the standard deviation of the intercept (response), $s$, and the slope estimated, $S$, from the calibration curve of the analytes. ${ }^{36}$

The precision of the method was evaluated in terms of repeatability and intermediate precision expressed as relative standard deviation ( $\mathrm{RSD} \%)$. The repeatability was verified by carrying out 8 injections of a1 $\mu \mathrm{g} \mathrm{mL}^{-1}$ standard solutions in a single day while maintaining constant all the operational conditions. The intermediate precision was obtained performing 8 injections of the same standard solution in three different days. The RSD was calculated using the average of the retention times and also the relative areas for each pesticide. The accuracy of a method is the systematic error of that measuring system and was evaluated by carrying out recovery assays. ${ }^{35,36}$

\section{Results and Discussion}

\section{Method validation}

The calibration curve equation, determination coefficient $\left(r^{2}\right)$, LOD and LOQ are summarized in Table 2. Regression coefficients of the calibration curves for all analytes ranged from 0.9997 and 0.9821 , and the values of the detection and quantification limits were lower than those prescribed by regulatory agencies such as USEPA, ${ }^{37} \mathrm{EU}^{38}$ and ANVISA. ${ }^{39}$ Repeatability and intermediate precision (RSD) for the retention times of pesticides were between 0.003 and $<0.001 \%$, and $0.032-0.142 \%$, respectively. The same parameters related to chromatographic areas ranged from 0.4 to $11.0 \%$ and 2.1 to $15.6 \%$, respectively. Regarding method precision, RSD up to $20 \%$ are acceptable, depending on the complexity of the sample. ${ }^{40}$ Therefore results obtained in this work may be considered appropriate. Figure 1 shows a representative chromatogram of the standard working solution, whose peaks have their characteristic ions presented in Table 1.

Recoveries obtained in the extraction of lyophilized carrots are shown in Table 3, and are in the range of 70 to $133 \%$ for eleven analytes. However, lower recoveries were gotten for trifluralin and iprodione and higher recoveries for fenthion. Those results may be due to stronger matrix/ analyte interactions and to co-elution of interferents,

Table 2. Results obtained for the calibration curves of pesticides, values of LOD and LOQ obtained by GC/MS

\begin{tabular}{|c|c|c|c|c|}
\hline Pesticides & Equation $(y=a x+b)$ & $r^{2}$ & $\mathrm{LOD}\left(\mathrm{mg} \mathrm{kg}^{-1}\right)$ & $\operatorname{LOQ}\left(\mathrm{mg} \mathrm{kg}^{-1}\right)$ \\
\hline Trichlorphon & $y=0.0267 x+0.0042$ & 0.9963 & 0.0310 & 0.0940 \\
\hline Trifluralin & $y=0.2650 x-0.0135$ & 0.9957 & 0.0240 & 0.0729 \\
\hline Dicloran & $y=0.1172 x-0.0030$ & 0.9994 & 0.0304 & 0.0920 \\
\hline Chlorothalonil & $y=0.4354 x+0.0040$ & 0.9997 & 0.0292 & 0.0886 \\
\hline Prometryn & $y=0.3513 x+0.0151$ & 0.9991 & 0.0024 & 0.0072 \\
\hline Linuron & $y=0.0768 x-0.0090$ & 0.9877 & 0.0540 & 0.1637 \\
\hline Malathion & $y=0.1647 x-0.0035$ & 0.9977 & 0.0607 & 0.1840 \\
\hline Fenthion & $y=0.4479 x-0.0003$ & 0.9994 & 0.0152 & 0.0461 \\
\hline Captan & $y=0.0102 x-0.0010$ & 0.9877 & 0.1968 & 0.5963 \\
\hline Folpet & $y=0.0041 x-0.0005$ & 0.9863 & 0.1584 & 0.4800 \\
\hline Procymidone & $y=0.3655 x+0.0251$ & 0.9980 & 0.0072 & 0.0219 \\
\hline Iprodione & $y=0.1011 x-0.0056$ & 0.9965 & 0.0236 & 0.0716 \\
\hline Prochloraz & $y=0.0822 x-0.0102$ & 0.9834 & 0.0266 & 0.0806 \\
\hline Deltamethrin & $y=0.0864 x-0.0118$ & 0.9821 & 0.0154 & 0.0467 \\
\hline
\end{tabular}




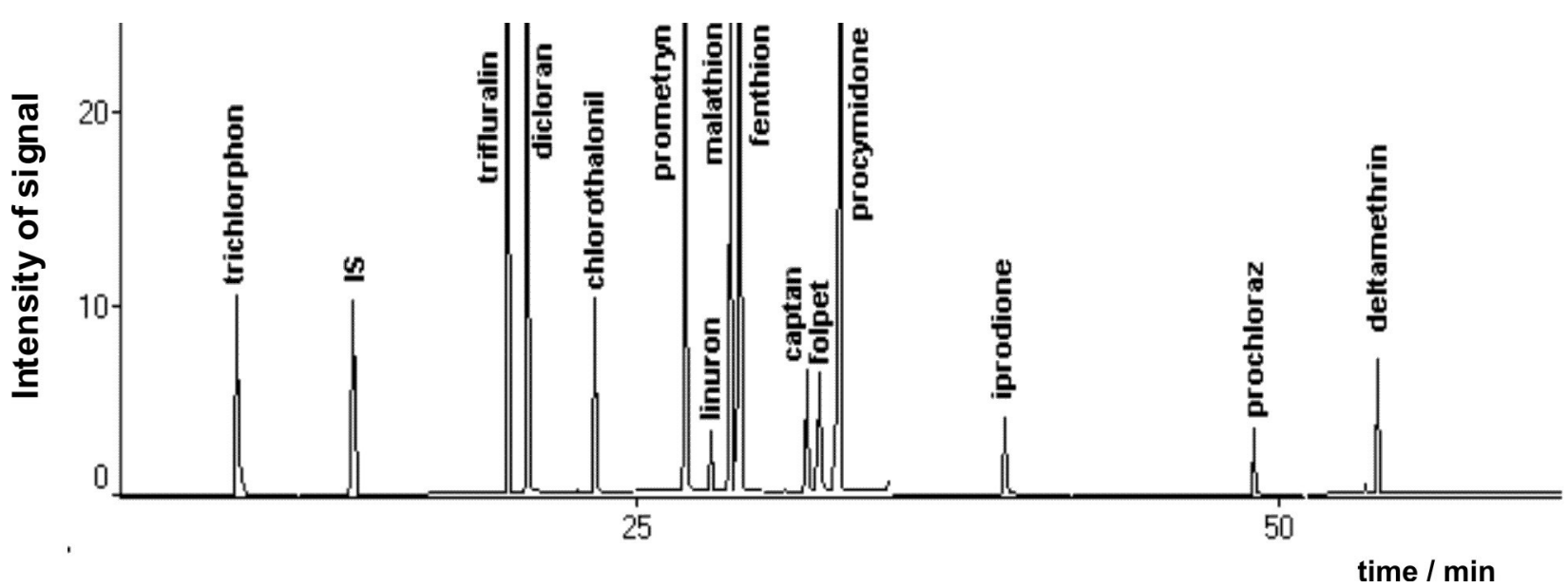

Figure 1. Representative chromatogram of the standard working solution. Chromatographic conditions are described in the Experimental section.

respectively. The use of dichloromethane and ethyl acetate as extracting solvents resulted in good recoveries specially for 5 to 7 analytes, when C18, XAD-4 e XAD-7 solid phases were employed. Figure 2A presents a chromatogram of an extraction blank obtained from a free pesticide carrot sample, while Figure 2B shows a chromatogram obtained from MSPD/PLE of a spiked carrot sample where sodium sulphate was employed. It is possible to observe from Table 3 that the use of sodium sulphate or XAD-7 provided the better recovery values for seven pesticides, when using ethyl acetate. Acetone and florisil provided lower efficiency for the extraction process for the majority of the pesticides. Relative standard deviations are in the range of 2 to $31 \%$ whenever recovery values were satisfactory. However, it can be seen that RSD are not acceptable when there were difficulties in the extraction process due to matrix/interferents influence.
Besides that, the use of drying agents (anhydrous sodium sulphate and Celite) also resulted in recoveries in the range of 70 to $133 \%$. This indicates that the use of the solid phases did not improve the extraction process efficiency significantly. However, several chromatograms obtained when solid phases were added to the extraction process resulted in lower intensity interferents peaks, providing an analytical method less prone to interferences. This can be observed in Figure $2 \mathrm{C}$ that shows the chromatogram obtained with XAD-7 and ethyl acetate as extracting solvent. Distorted procymidone chromatographic peak (Figure 2B) is an example of the interference which occurred without using dispersion agent, which is not seen in Figure 2C. Results obtained with wet carrots were not satisfactory, as most of the recoveries values were below $70 \%$. The presence of water molecules in the matrix may

Table 3. Recovery percentage (standard deviation) obtained for 14 pesticides using various solid phases and extracting solvents in a MSPD/PLE of freezedried carrots

\begin{tabular}{|c|c|c|c|c|c|c|c|c|c|c|c|c|c|c|c|}
\hline \multirow[t]{2}{*}{ Analyte } & \multicolumn{5}{|c|}{ Dichloromethane } & \multicolumn{5}{|c|}{ Ethyl Acetate } & \multicolumn{5}{|c|}{ Acetone } \\
\hline & $\mathrm{C} 18$ & XAD-4 & XAD-7 & Florisil & Sulphate & $\mathrm{C} 18$ & XAD-4 & XAD-7 & Florisil & Sulphate & $\mathrm{C} 18$ & XAD-4 & XAD-7 & Florisil & Celite \\
\hline Trichlorphon & $84(29)$ & $86(4)$ & $\mathbf{9 0}(22)$ & $18(3)$ & $73(17)$ & $\mathbf{7 0}(20)$ & 99(10) & $80(6)$ & $43(3)$ & 92(13) & $57(1)$ & $34(1)$ & $34(5)$ & $29(4)$ & $48(13)$ \\
\hline Trifluralin & $47(12)$ & $45(3)$ & $51(10)$ & $26(5)$ & $22(5)$ & $17(2)$ & $37(12)$ & $43(3)$ & $26(2)$ & $41(17)$ & $28(7)$ & $26(1)$ & $17(4)$ & $29(6)$ & $34(8)$ \\
\hline Dicloran & $\mathbf{8 8}(30)$ & 81(10) & 81(18) & $50(9)$ & $52(13)$ & $45(11)$ & $\mathbf{9 3}(20)$ & $67(41)$ & $58(10)$ & 87(19) & $60(6)$ & $39(1)$ & $35(1)$ & $44(7)$ & $57(15)$ \\
\hline Chlorothalonil & $200(64)$ & $176(42)$ & $123(1)$ & $155(4)$ & $152(20)$ & $484(66)$ & $369(16)$ & 77(11) & $215(21)$ & $484(131)$ & $118(17)$ & $46(4)$ & $8(1)$ & $10(1)$ & $\mathbf{7 4}(31)$ \\
\hline Prometryn & $155(10)$ & $234(11)$ & $158(40)$ & $104(4)$ & $90(6)$ & $\mathbf{9 3}(41)$ & $291(27)$ & $137(2)$ & $177(46)$ & 175(59) & $167(30)$ & $63(22)$ & $59(7)$ & $119(11)$ & 104(20) \\
\hline Linuron & $50(18)$ & $66(13)$ & $52(37)$ & $\mathbf{8 5}(37)$ & $15(1)$ & $89(5)$ & $113(22)$ & $51(36)$ & $51(9)$ & $\mathbf{8 8}(10)$ & $\mathbf{7 4}(20)$ & $50(11)$ & $21(2)$ & $41(11)$ & $38(11)$ \\
\hline Malathion & $189(28)$ & $160(7)$ & $183(46)$ & $\mathbf{7 6}(21)$ & $106(28)$ & $179(29)$ & $274(72)$ & $130(12)$ & $146(31)$ & $170(69)$ & $129(3)$ & $85(7)$ & $71(2)$ & $80(5)$ & $123(28)$ \\
\hline Fenthion & $337(19)$ & $343(46)$ & 472(19) & $49(11)$ & $243(25)$ & $273(30)$ & $674(38)$ & $415(23)$ & $25(9)$ & $325(13)$ & $318(6)$ & 271(16) & $196(16)$ & $29(6)$ & $352(14)$ \\
\hline Captan & $59(81)$ & $45(13)$ & $50(12)$ & $26(6)$ & $32(15)$ & $118(2)$ & $113(3)$ & $18(4)$ & $20(15)$ & $74(16)$ & $12(1)$ & 11(1) & $9(1)$ & $7(1)$ & $31(19)$ \\
\hline Folpet & $133(14)$ & 111(14) & 92(15) & $86(5)$ & $152(63)$ & $207(22)$ & $277(80)$ & $\mathbf{7 3}(12)$ & $173(44)$ & $256(28)$ & 91(14) & $61(2)$ & $48(6)$ & $44(1)$ & $125(22)$ \\
\hline Procymidone & $102(8)$ & $97(16)$ & $79(18)$ & $56(8)$ & $107(24)$ & $126(3)$ & $127(24)$ & $70(3)$ & 82(14) & $121(23)$ & $85(6)$ & $47(2)$ & $45(4)$ & $55(9)$ & $80(23)$ \\
\hline Iprodione & $27(12)$ & $23(2)$ & $18(2)$ & $21(5)$ & $31(14)$ & $22(3)$ & $30(2)$ & $19(3)$ & $20(1)$ & $34(13)$ & $23(3)$ & $9(1)$ & $12(2)$ & $14(2)$ & $24(9)$ \\
\hline Prochloraz & $118(27)$ & $\mathbf{9 2}(22)$ & 64(11) & $41(6)$ & $\mathbf{8 5}(25)$ & $52(12)$ & $102(22)$ & $\mathbf{8 7}(21)$ & 31(17) & $\mathbf{7 4}(32)$ & $52(9)$ & $29(5)$ & $34(6)$ & $31(7)$ & $69(36)$ \\
\hline Deltamethrin & $73(25)$ & $77(15)$ & $\mathbf{7 8}(15)$ & $31(7)$ & $\mathbf{7 5}(26)$ & $50(18)$ & $14(5)$ & $\mathbf{8 3}(8)$ & $50(9)$ & 81(27) & $63(5)$ & $32(1)$ & $46(1)$ & $46(4)$ & $84(22)$ \\
\hline
\end{tabular}

Recoveries between 70 and $135 \%$ are written in bold. Data were obtained from replicate experiments. 


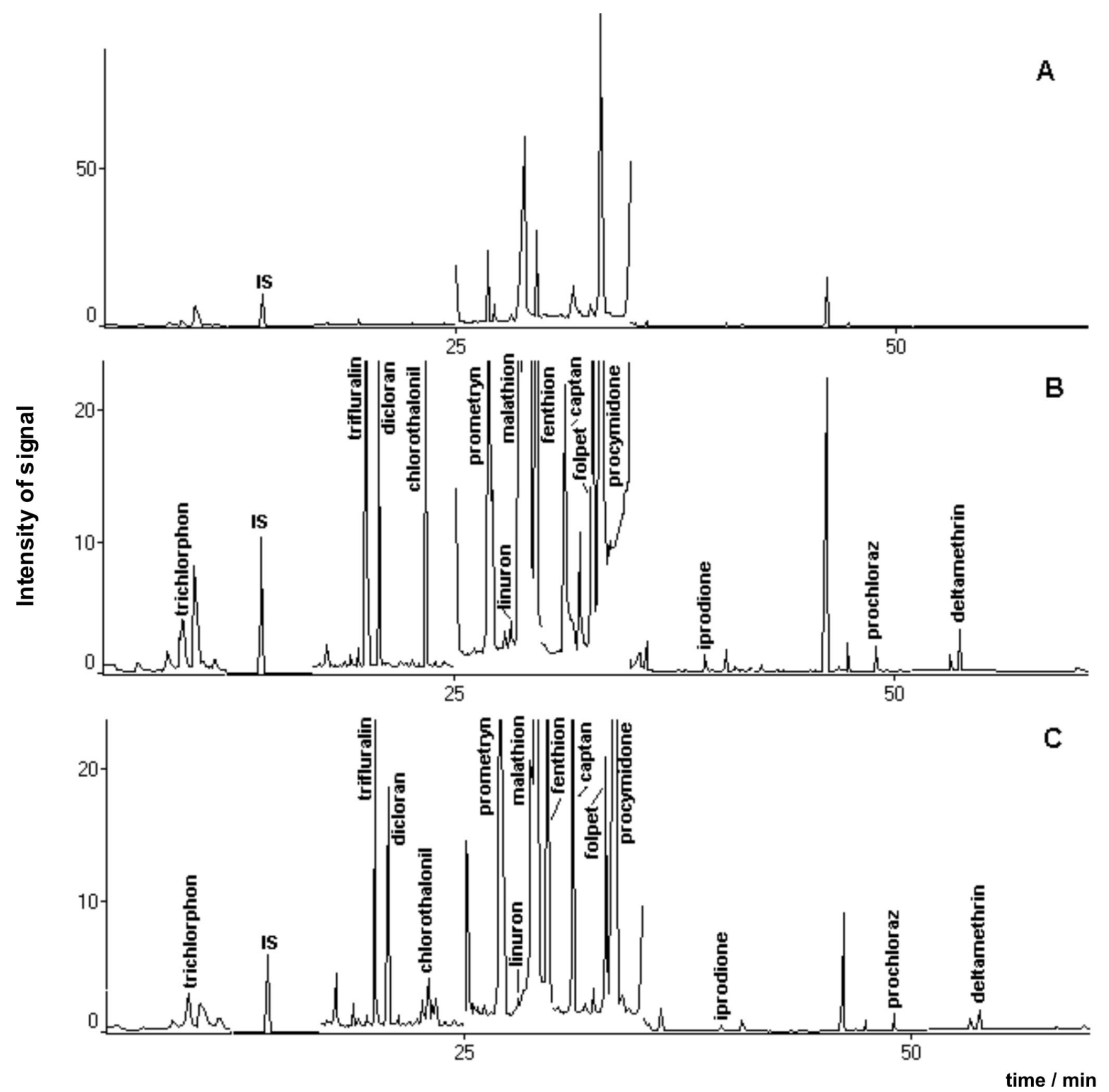

Figure 2. A - Chromatogram of an extraction blank obtained from a free pesticide carrot sample. B - Chromatogram of the 14 pesticides extracted from freeze-dried carrots using ethyl acetate and anhydrous sodium sulphate. C - Chromatogram of the 14 pesticides extracted from freeze-dried carrots using ethyl acetate and XAD-7. Final concentration of $0.5 \mu \mathrm{g} \mathrm{g}^{-1}$ on a wet basis. Chromatographic conditions are described in the Experimental section.

hinder the interaction among solid phase and the analytes or prevent the access of extracting solvents to them. Mean values for the humidity of freeze-dried carrots were about $3.0 \%$, while for wet samples they were $90.1 \%$. Relative standard deviations for humidity determinations were 0.33 and $0.25 \%$ respectively.

\section{Real samples}

Two samples of commercial freeze-dried carrots (SP4 and RS2) were analyzed using two different MSPD/PLE methods: XAD-7 (method A) and anhydrous sodium sulphate (method B) as dispersion agents and ethyl acetate as solvent. Ten pesticides were analyzed using these two methods: deltamethrin, prochloraz, procymidone and trichlorphon with both methods; chlorothalonil, folpet and malathion with method A; captan, dicloran, and linuron with method B.

Table 4 shows the amount of pesticides found in samples of freeze-dried carrots. Six residues were found above LOQ values in both samples, using method B: trichlorphon, dicloran, captan, procymidone, prochloraz and deltamethrin. The application of method A resulted in concentrations above the LOQ for 4 and 6 pesticides in 
Table 4. Pesticides contents found in carrot samples ( $\mathrm{mg} \mathrm{kg}^{-1}$ ) using the MSPD/PLE proposed method for freeze-dried carrots with two different sorbent phases and ethyl acetate in comparison with MRL from several agencies

\begin{tabular}{|c|c|c|c|c|c|c|c|}
\hline \multirow[b]{3}{*}{ Analyte } & \multicolumn{2}{|c|}{ Sample 1, SP4 } & \multicolumn{2}{|c|}{ Sample 2, RS2 } & \multicolumn{3}{|c|}{$\mathrm{MRL}^{*}\left(\mathrm{mg} \mathrm{kg}^{-1}\right)$} \\
\hline & \multicolumn{4}{|c|}{ Sorbent phase } & \multirow[b]{2}{*}{$\mathrm{EU}^{\mathrm{a}}$} & \multirow[b]{2}{*}{ USEPA $^{\mathrm{b}}$} & \multirow[b]{2}{*}{ ANVISA } \\
\hline & $\begin{array}{c}\text { XAD-7 } \\
(\mathrm{RSD} \%)\end{array}$ & $\begin{array}{l}\text { Anhydrous sodium } \\
\text { sulphate (RSD \%) }\end{array}$ & $\begin{array}{l}\text { XAD-7 } \\
(\text { RSD \%) }\end{array}$ & $\begin{array}{l}\text { Anhydrous sodium } \\
\text { sulphate (RSD \%) }\end{array}$ & & & \\
\hline Trichlorphon & $0.55(18.7)$ & $0.57(9.3)$ & $1.54(7.3)$ & $1.32(15.7)$ & 0.5 & n.e. & 0.05 \\
\hline Dicloran & n.a. & $0.21(6.7)$ & n.a. & $0.22(15.2)$ & n.e. & 10 & n.e. \\
\hline Chlorothalonil & $<\mathrm{LOD}$ & n.a. & $<$ LOD & n.a. & 1.0 & 1.0 & 0.5 \\
\hline Malathion & $<\mathrm{LOQ}$ & n.a. & $0.38(6.0)$ & n.a. & 0.5 & 8.0 & n.e. \\
\hline Folpet & $<\mathrm{LOQ}$ & n.a. & $7.61(11.3)$ & n.a. & 0.1 & n.e. & n.e. \\
\hline Linuron & n.a. & $<\mathrm{LOQ}$ & n.a. & $<\mathrm{LOQ}$ & n.e. & 1.0 & 1.0 \\
\hline Captan & n.a. & $2.97(4.2)$ & n.a. & $1.65(12.3)$ & 0.1 & 2.0 & n.e. \\
\hline Procymidone & $0.08(6.9)$ & $0.06(3.7)$ & $0.18(10.4)$ & $0.24(4.1)$ & 0.02 & n.e. & 1.0 \\
\hline Prochloraz & $0.14(7.5)$ & $0.14(5.2)$ & $0.14(7.6)$ & $0.15(18.7)$ & 0.05 & n.e. & 0.5 \\
\hline Deltamethrin & $0.19(9.4)$ & $0.21(10.4)$ & $0.27(6.9)$ & $0.22(17.6)$ & 0.05 & n.e. & n.e. \\
\hline
\end{tabular}

Each sample was extracted 3 times and each extract was analyzed 5 times (n=15). *MRL: maximum residue limit; n.a.: not analyzed; n.e.: not established

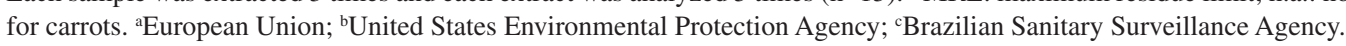

samples 1 and 2, respectively: trichlorphon, procymidone, prochloraz and deltamethrin (plus malathion and folpet).

Prochloraz and procymidone showed concentrations below the MRL set by ANVISA, but higher than that for the European Community. Trichlorfon was detected at levels above those established by EU and ANVISA, while chlorothalonil and malathion were found in lower amounts than those determined by all the agencies. ANVISA does not prescribe the use of folpet and deltamethrin, for growing carrots. However the levels found for both analytes in the investigated samples are above the MRL designated by EU.

Method B allowed the detection of seven compounds in both samples. Concentrations of dichloran and linuron were below the maximum residue limits set by the three regulatory agencies quoted. Captan and deltamethrin were found in concentrations above those values set as safe by the EU, although these two compounds are not regulated by USEPA and ANVISA for the culture of carrots. Procymidone and prochloraz were detected at concentrations below those recommended by ANVISA but above the MRL designated by EU. The use of trichlorfon is not allowed for carrot culture according to USEPA, but was found in concentrations above the MRL set by EU and ANVISA.

\section{Conclusions}

The proposed extraction methods proved to be efficient for the determination of ten pesticides in liophylized carrots, as recovery values ranged from 70 to $130 \%$ for the method A (XAD-7 as dispersion agent) and 74 to $121 \%$ for the method B (anhydrous sodium sulphate as dispersion agent). Results obtained with wet carrots were not satisfactory, as most of the recoveries values were below $70 \%$. The use of C18, XAD-4 e XAD-7 solid phases as dispersion agents and of dichloromethane and ethyl acetate as extracting solvents provided the best results in the MSPD/PLE processes. Good recoveries were obtained also when drying agents (sodium sulphate and Celite) were employed. The use of drying agent (anhydrous sodium sulfate) gave recoveries similar to those obtained with C18, XAD-4 and XAD-7 solid phases, indicating that these dispersion agents did not improve the extraction process. Employing acetone as solvent resulted in low recoveries, however, when using $\mathrm{C} 18$ and Celite acceptable values were achieved for five and six compounds, respectively. The presence of water molecules in the matrix may hinder the interaction among solid phase and the analytes or prevent the access of extracting solvents to them. LOD and LOQ were well below the MRL recommended by Brazilian, North American and European regulatory agencies.

\section{Acknowledgments}

The authors thank CNPq, CAPES and FAPERGS for financial support and scholarships and also Andréia L. Silva for humidity measurements. We also thank Ewelin M. P. N. Canizzares from FEPAM for the use of GC/MS equipment.

\section{References}

1. Stajnbaher, D.; Zupancic, L. K.; J. Chromatogr. A 2003, 1015, 185. 
2. Pittertschatscher, K.; Inreiter, N.; Schatzl, A.; Malissa, H. Jr.; Fresenius J. Anal. Chem. 1999, 365, 338.

3. Agüera, A.; Contreras, M.; Crespo, J.; Fernández-Alba, A. R.; Analyst 2002, 127, 347.

4. Gfrerer, M.; Chen, S.; Lankmayr, E. P.; Quan, X.; Yang, F.; Anal. Bioanal. Chem. 2004, 378, 1861.

5. Lambropoulou, D. A.; Albanis, T. A.; Anal. Bioanal. Chem. 2007, 389, 1663.

6. Abbas, K. A.; Mohamed, A.; Abdulamir, A. S.; Abas, H. A.; Am. J. Biochem. Biotechnol. 2008, 4, 345.

7. Beyer, A.; Biziuk, M.; Food Chem. 2008, 108, 669.

8. López, B. G.; Reyes, J. F. G.; Díaz, A. M.; Talanta 2009, 79, 109.

9. Richter, B. E.; Jones, B. A.; Ezzel, J. L.; Porter, N. L.; Avdalovic, N.; Pohl, C.; Anal. Chem. 1996, 68, 1033.

10. Lehotay, S.; Lee, C.; J. Chromatogr. A 1997, 785, 313.

11. Vidal, J. L. M.; Arrebola, F. J.; Sánchez, M. M.; J. Chromatogr. A 2002, 959, 203.

12. Chuang, J. C.; Hart, K.; Chang, J. S.; Boman, L. E.; van Emon, J. M.; Reed, A. W.; Anal. Chim. Acta 2001, 444, 87.

13. Arrebola, F. J.; Vidal, J. L. M.; Sánchez M. M.; Castellón, F. J. A.; Anal. Chim. Acta 2003, 484, 167.

14. Moreno, J. L. F.; Liebanas, F. J. A.; Frenich, A. G.; Vidal, J. L. M.; J. Chromatogr. A 2006, 1111, 97.

15. Frenich, A. G.; Salvador, I. M.; Vidal, J. L. M.; Lopes, W. G.; Lopes, T. L.; Anal. Bioanal. Chem. 2005, 383, 1106.

16. Barker, S. A.; Long, A. R.; Short, C. R.; J. Chromatogr. A 1989 , $475,353$.

17. Garcinuño, R. M.; Ramos, L.; Hernando, P. F.; Cámara, C.; J. Chromatogr. A 2004, 1041, 35.

18. Bogialli S.; Di Corcia A.; J. Biochem. Biophys. Methods 2007, $70,163$.

19. Tekel, J.; Hatrík, S.; J. Chromatogr. A 1996, 754, 397.

20. Dórea, H. S.; Sobrinho, L. L.; J. Braz. Chem. Soc. 2004, 15, 690.

21. Barker, S. A.; J. Biochem. Biophys. Methods 2007, 70, 151.

22. Picó, Y.; Fernández, M.; Ruiz, M. J.; Font, G.; J. Biochem. Biophys. Methods 2007, 70, 117.

23. Martínez, R. C.; Gonzalo, E. R.; Ruiz, P. R.; Méndez, J. H.; J. Chromatogr. A 2005, 1089, 1.
24. Bogialli, S.; Curini, R.; Di Corcia, A.; Lagana, A.; Nazzari, M.; Tonci, M.; J. Chromatogr. A 2004, 1054, 351.

25. Bogialli, S.; Curini, R.; Di Corcia, A.; Lagana, A.; Nazzari, M.; Tamburro, J.; J. Agric. Food Chem. 2004, 52, 665.

26. Gentili, A.; Perret, D.; Marchese, S.; Sergi, M.; Olmi, C.; Curini, R.; J. Agric. Food Chem. 2004, 52, 4614.

27. Vonderheide, A. P.; Kauffman, P. E.; Hieber, T. E.; Brisbin, J. A.; Melnyk, L. J.; Morgan, J. N.; J. Agric. Food Chem. 2009, 57, 2096.

28. Pereira, M. B.; Castro, M. J. G.; Lorenzo, S. M.; Mahía, P. L.; Rodríguez, D. P.; Fernández, E. F.; Talanta 2007, 71, 1345.

29. Soler, C.; James, K. J.; Picó, Y.; J. Chromatogr. A 2007, 1157, 73.

30. Doong, R.; Chang, S.; Sun, Y.; J. Chromatogr. A 2000, 879, 177.

31. Kawata, K.; Asada, T.; Oikawa, K.; J. Chromatogr. A 2005 , 1090,10.

32. Taylor, J. K.; Anal. Chem. 1983, 55, 600A.

33. European Comission, Method Validation and Quality Control Procedures for Pesticide Residues Analysis in Food and Feed, 2007.

34. Vial, J.; Jardy, A.; Anal. Chem. 1999, 71, 2672.

35. CITAC/Eurachem, Guide to Quality in Analytical Chemistry: An Aid to Accreditation, 2002.

36. ICH - International Conference on Harmonisation of Technical Requirements for Registration of Pharmaceuticals for Human Use, Q2B Validation of Analytical Procedures: Methodology. 1996.

37. http://www.epa.gov/pesticides/food/viewtols.htm, accessed in January 2008.

38. http://ec.europa.eu/food/plant/protection/pesticides/index_ en.htm, accessed in January 2008.

39. http://www.anvisa.gov.br/toxicologia/sia.htm, accessed in January 2008.

40. Ribani, M.; Bottoli, C. B. G.; Collins, C. H.; Jardim, I. C. S. F.; Melo, L. F. C.; Quim. Nova 2004, 27, 771.

Received: June 10, 2009

Web Release Date: December 3, 2009 